\title{
A confidential enquiry into cases of neonatal encephalopathy
}

\author{
E S Draper, J J Kurinczuk, C R Lamming, M Clarke, D James, D Field
}

See end of article for authors' affiliations

Correspondence to:

Elizabeth S Draper Department of Epidemiology and Public Health, University of Leicester, 22-28 Princess Road West, Leicester,

LE1 6TP, UK; msn@le.ac.uk

Accepted 22 May 2002

\begin{abstract}
Objectives: To assess the quality of care and timing of possible asphyxial events for infants with neonatal encephalopathy; to compare the quality of care findings with those relating to the deaths from the Confidential Enquiry into Stillbirths and Deaths in Infancy (CESDI); and to assess whether the confidential enquiry method is a useful clinical governance tool for investigating morbidity.

Design: Independent, anonymised, multidisciplinary case reviews.

Setting: Trent Health Region, UK.

Patients: All cases of grade II and III neonatal encephalopathy born in 1997, excluding those due to congenital malformation, inborn error of metabolism, or infection. All CESDI deaths thought to have resulted from intrapartum asphyxia in 1996 and 1997.

Main measures: Quality of care provided, timing of possible asphyxial episodes, and the source and timing of episodes of suboptimal care.

Results: Significant or major episodes of suboptimal care were identified for $64 \%$ of the encephalopathy cases and $75 \%$ of the deaths. An average of 2.8 and 2.5 episodes of suboptimal care were identified for the deaths and encephalopathy cases respectively. Over $90 \%$ of episodes involved the care provided by health professionals. Results were fed directly back to the units concerned on request and changes in practice have been reported.

Conclusions: The findings were very similar for the encephalopathy cases and the deaths. We have demonstrated that with minor adaptations the CESDI process can be applied to serious cases of morbidity. However, explicit quality standards, control data, and a more formal mechanism for the implementation of findings would strengthen the confidential enquiry process as part of clinical governance.
\end{abstract}

$\mathrm{N}$ eonatal encephalopathy was defined by Nelson and Leviton as "A clinically defined syndrome of disturbed neurological function in the earliest days of life in the term infant, manifested by difficulty with initiating and maintaining respiration, depression of tone and reflexes, subnormal level of consciousness, and often by seizures." ${ }^{11}$ Evidence suggests that both antepartum factors and intrapartum events are important in the aetiology of neonatal encephalopathy. ${ }^{2-6}$ Neonatal encephalopathy is likely to be part of the same spectrum of causal pathways that can result in stillbirth or neonatal death. Which of these three outcomes occurs in any particular situation, is likely to be due to the combination of the timing and severity of the insult, together with the constitutional susceptibility of the fetus and the care provided. Therefore these infants represent an ideal group in which to explore issues of quality of care.

In England, Wales, and Northern Ireland stillbirths and neonatal deaths thought to have resulted from intrapartum asphyxia were the subject of full confidential enquiries during the first three years (1993-1995) of the national programme of Confidential Enquiries into Stillbirths and Deaths in Infancy (CESDI). ${ }^{7}$ This group of deaths was chosen as the focus of the enquiries as they were considered to be the group most likely to directly benefit from improvements in perinatal care. In Trent Region these deaths continued to be the subject of full enquiries until the end of $1997 .{ }^{8}$ Infants who experienced an intrapartum insult but survived and developed neonatal encephalopathy were obviously not included in the CESDI programme despite potential similarities.

The aims of this study were first, to use the confidential enquiry process to review the care of infants with neonatal encephalopathy who survived the neonatal period, to assess the quality of care provided including the timing of possible asphyxial episodes. Second, to compare the quality of care findings with the results from the confidential enquiries into deaths in the first 28 days of life thought to be due to an intrapartum cause. Finally, to assess whether this confidential enquiry process can be used as a clinical governance tool to investigate cases of morbidity rather than deaths.

\section{METHODS}

Infants with grade II or grade III neonatal encephalopathy were included in the study if they fulfilled the criteria in box 1. All infants in Trent presenting with grade II or grade III neonatal encephalopathy in 1997, who were admitted for neonatal care were included in the Trent Neonatal Survey, ${ }^{9}$ which provided the sample for the study. To exclude cases due to congenital malformation, inborn error of metabolism, or infection, all the cases were reviewed by a consultant neonatologist (DF). The remaining case notes were anonymised in the prescribed manner for CESDI enquires and checked for completeness. ${ }^{7}$ Copies of the anonymised notes were sent to the panel members. Each of the nine panels consisted of an obstetrician, neonatologist, epidemiologist, midwife, neonatal nurse, and study facilitator. In order to standardise the running of the panels the same epidemiologist (ESD, chair) and study facilitator (CRL) attended all the panel discussions; neither participated in the decision making process. Panel members were selected from a pool of experienced practitioners in each specialty all of whom had previously been involved in CESDI panels. No panel members reviewed cases from their own unit. The quality of care was considered for the antepartum, intrapartum, and neonatal periods. For each case a clinical judgement was made as to the presence or absence of episodes of suboptimal care within each period. 
Box 1 Inclusion criteria for cases of grades II and III neonatal encephalopathy*

Infants were defined as cases if the fulfilled criteria 1 and 2 PLUS 3 or 4

1. 35 weeks gestation or greater at delivery and had no major congenital anomaly, infection or an inborn error of metabolism evident during the period of neonatal care; AND

2. survival for more than 28 days;

PLUS presentation in the first 48 hours after birth with:

3. neurological disturbance causing as a minimum treated "fits" (grade II);

$\mathrm{OR}$

4. neurological disturbance so severe that the baby required ventilatory support (grade III)

${ }^{*}$ Modified from Sarnat \& Sarnat 1976. ${ }^{10}$

Table 1 Overall levels of suboptimal care and relevance to the encephalopathy

\begin{tabular}{ll}
\hline $\begin{array}{l}\text { Level of suboptimal } \\
\text { care }\end{array}$ & Definition \\
\hline O- none & $\begin{array}{l}\text { No suboptimal care } \\
\text { Suboptimal care, but different management } \\
\text { would have made no difference to the } \\
\text { outcome } \\
\text { Suboptimal care, in which different } \\
\text { management might have made a difference } \\
\text { to the outcome } \\
\text { II - significant }\end{array}$ \\
III - major & $\begin{array}{l}\text { Subopalimal care, in which different } \\
\text { to have made a difference to the outcome. }\end{array}$ \\
\hline
\end{tabular}

The suboptimal care was graded using an adaptation of the notable factors grid from CESDI (table 1 ). ${ }^{7}$ The timing of any apparent asphyxial episode was ascribed to the appropriate period using the answers to the following questions: (i) Is there evidence of a peripartum insult? (ii) Does the peripartum insult alone account for the clinical condition of the baby? (iii) Is there evidence of an antepartum insult in this case?

Comparisons were made between the findings for the cases with neonatal encephalopathy and the Trent CESDI deaths with a birth weight of at least 1500 grams, thought to be due to an intrapartum cause from 1996 and 1997.

\section{Analysis}

Statistical significance tests were carried out using the standard $\chi^{2}$ test for association and Fishers Exact test where appropriate. Ninety five per cent confidence intervals (95\% CI) for proportions were estimated using the exact binomial distribution.

\section{RESULTS}

During 1997, 49 relevant cases of grade II or III neonatal encephalopathy were identified: a birth prevalence of 0.82 per 1000 total live births. There were 59 deaths with evidence of intrapartum asphyxia of which $29(49 \%)$ were stillbirths and $30(51 \%)$ were neonatal deaths. Of the encephalopathy cases, $34(69 \%)$ were grade II and $15(31 \%)$ were grade III. Table 2 gives the level of suboptimal care identified by the confidential enquiry. Significant or major episodes of suboptimal care at some stage in pregnancy, labour or after delivery were identified for 31 (64\%; $95 \%$ CI $48 \%$ to $77 \%$ ) of the encephalopathy cases and 44 (75\%; $95 \%$ CI $62 \%$ to $85 \%$ ) of the deaths; this difference was not statistically significant $(\mathrm{p}=0.29)$.
Table 2 Grade of neonatal encephalopathy by overall level of suboptimal care $(n=49)$

\begin{tabular}{|c|c|c|c|c|c|c|}
\hline \multirow{3}{*}{$\begin{array}{l}\text { Level of } \\
\text { suboptimal care }\end{array}$} & \multicolumn{6}{|c|}{ Grade of neonatal encephalopathy } \\
\hline & \multicolumn{2}{|l|}{ II } & \multicolumn{2}{|l|}{ III } & \multicolumn{2}{|c|}{ All cases } \\
\hline & $\mathrm{n}$ & $\%$ & $\mathrm{n}$ & $\%$ & $\mathrm{n}$ & $\%$ \\
\hline None & 4 & 12 & 3 & 20 & 7 & 14 \\
\hline Minor & 8 & 24 & 3 & 20 & 11 & 22 \\
\hline Significant & 7 & 21 & 6 & 40 & 13 & 27 \\
\hline Major & 15 & 44 & 3 & 20 & 18 & 37 \\
\hline All levels & 34 & 100 & 15 & 100 & 49 & 100 \\
\hline
\end{tabular}

Table 3 summarises the timing and source of the significant and major episodes of suboptimal care identified for the encephalopathy cases and the deaths. The average number of episodes of suboptimal care was 2.8 for the deaths and 2.5 for the encephalopathy cases $(25 \%$ of deaths and $30 \%$ of encephalopathy cases had one or no episodes of suboptimal care). These episodes involved the care provided by health professionals for $93 \%$ of the deaths and $96 \%$ of the encephalopathy cases. Table 4 summarises the nature of the episodes of suboptimal care that were identified using the categories of suboptimal care from CESDI. ${ }^{8}$ Similar proportions of episodes were identified for most categories of suboptimal care. However, there were significantly more delays in communication identified during labour for the encephalopathy cases than the deaths $(41 \% \quad v \quad 22 \%$ respectively; $\mathrm{p}=0.03)$. Postnatally, a significantly higher proportion of episodes of poor or inappropriate surveillance of the infants with encephalopathy was identified compared to the neonatal deaths $(25 \% \vee 7 \%$ respectively; $\mathrm{p}=0.044)$.

The proportion of encephalopathy cases with evidence of an antepartum and/or peripartum insult is given in table 5 . There was evidence of a peripartum insult in $88 \%$ (95\% CI $75 \%$ to $95 \%$ ) of encephalopathy cases. However, in the opinion of the panels reviewing the cases, the peripartum insult alone was thought likely to account for the clinical condition of the case in only $45 \%$ (95\% CI $31 \%$ to $60 \%$ ) of cases. On the basis of the information reviewed, evidence of an antepartum insult was, in the view of the panels, apparent for only 18\% (95\% CI 9\% to $32 \%$ ) of cases, all of whom also had evidence of a peripartum insult.

\section{DISCUSSION}

The confidential enquiry method was first used in the UK to investigate the circumstances surrounding maternal deaths and has subsequently been adapted to investigate perioperative deaths, stillbirths, and deaths in infancy and most recently, suicides and homicides by people with mental illness. ${ }^{11}$ The purpose of these enquiries has been to identify avoidable factors in the circumstances surrounding each death with the aim of reducing mortality by improving standards. This is achieved in three ways. ${ }^{12}$ First, the knowledge that such enquires are being carried out may itself raise standards by making clinicians more aware and self critical of their practice. Second, by the production of formal reports of the analyses and recommendations of the enquiries, following which changes in practice may result. Finally, the participation of individual practitioners in the enquiry panels is itself an educational process that is anecdotally reported to cascade down to the units in which the individuals work. It is, however, clear that more formal, direct, and auditable mechanisms of implementation of the recommendations would strengthen the whole enquiry process. ${ }^{13}$ CESDI was developed as a completely anonymous process due to the concerns that the results of confidential enquiries might be used in legal 
Table 3 Timing and source of the episodes of significant and major suboptimal care identified

\begin{tabular}{|c|c|c|c|c|c|}
\hline \multicolumn{2}{|c|}{ Suboptimal care } & \multicolumn{2}{|c|}{ CESDI deaths } & \multicolumn{2}{|c|}{$\begin{array}{l}\text { Neonatal } \\
\text { encephalopathy cases }\end{array}$} \\
\hline Timing & Source & $\mathrm{n}$ & $\%$ & $\mathrm{n}$ & $\%$ \\
\hline \multirow[t]{2}{*}{ Antepartum } & Professional & 23 & 14 & 20 & 16 \\
\hline & Patient/family & 3 & 2 & 1 & 1 \\
\hline \multirow[t]{5}{*}{ Intrapartum } & Professional & 93 & 57 & 64 & 53 \\
\hline & Patient/family & 2 & 1 & 0 & - \\
\hline & Lack of human resources & 1 & 1 & 2 & 2 \\
\hline & Lack of equipment & 2 & 1 & 0 & - \\
\hline & Other & 3 & 2 & 0 & - \\
\hline \multirow[t]{4}{*}{ Postpartum } & Professional & 35 & 22 & 33 & 27 \\
\hline & Lack of human resources & 0 & - & 1 & 1 \\
\hline & Lack of equipment & 0 & - & 1 & 1 \\
\hline & Other & 1 & 1 & 0 & - \\
\hline All stages & & 163 & 100 & 122 & 100 \\
\hline
\end{tabular}

Table 4 Nature of the episodes of suboptimal care identified for the CESDI stillbirths and neonatal deaths and the cases of neonatal encephalopathy

\begin{tabular}{|c|c|c|c|c|}
\hline \multirow[b]{2}{*}{ Nature of the suboptimal care } & \multicolumn{2}{|c|}{$\begin{array}{l}\text { CESDI deaths } \\
(n=59)\end{array}$} & \multicolumn{2}{|c|}{$\begin{array}{l}\text { Neonatal } \\
\text { encephalopathy cases } \\
(n=49)\end{array}$} \\
\hline & $\mathrm{n}$ & $\%$ & $\mathrm{n}$ & $\%$ \\
\hline \multicolumn{5}{|l|}{ Failure to recognise a problem during labour: } \\
\hline Abnormal CTG or meconium & 21 & 35 & 12 & 25 \\
\hline Poor progress in labour & 2 & 3 & 0 & - \\
\hline \multicolumn{5}{|l|}{ Failure to act appropriately during labour: } \\
\hline No CTG performed despite indications & 4 & 7 & 0 & - \\
\hline Poor quality CTG & 7 & 12 & 0 & - \\
\hline Uterine stimulation despite fetal heart rate effects & 3 & 5 & 3 & 6 \\
\hline Delays in communication & 13 & 22 & 20 & 41 \\
\hline \multicolumn{5}{|l|}{ Failure to communicate during labour: } \\
\hline Abnormal CTG & 3 & 5 & 1 & 2 \\
\hline Call/inform more senior staff & 7 & 12 & 5 & 10 \\
\hline Paediatrican not called for delivery & 5 & 9 & 5 & 10 \\
\hline \multicolumn{5}{|l|}{ Failure to act appropriately after delivery: } \\
\hline Delayed/inappropriate resuscitation & 19 & 32 & 12 & 25 \\
\hline Poor/inappropriate surveillance & 2 & 7* & 12 & 25 \\
\hline
\end{tabular}

Table 5 Proportion of cases from the neonatal encephalopathy enquiries with evidence of an intrapartum or antepartum insult, Trent 1997

\begin{tabular}{|c|c|c|c|c|c|c|}
\hline & \multicolumn{2}{|c|}{ NE Grade II } & \multicolumn{2}{|c|}{ NE Grade III } & \multicolumn{2}{|l|}{ Total } \\
\hline & $\mathrm{n}$ & $\%$ & $\mathrm{n}$ & $\%$ & $\mathrm{n}$ & $\%$ \\
\hline $\begin{array}{l}\text { Evidence of peripartum insult present } \\
\text { The peripartum insult alone accounted for the condition of the baby } \\
\text { Evidence of an antepartum insult present }\end{array}$ & $\begin{array}{l}29(1)^{*} \\
15(6)^{*} \\
7(1)^{*}\end{array}$ & $\begin{array}{l}85 \\
44 \\
21\end{array}$ & $\begin{array}{l}14 \\
7(4)^{*} \\
2(1)^{*}\end{array}$ & $\begin{array}{l}93 \\
47 \\
13\end{array}$ & $\begin{aligned} 43 & (1)^{*} \\
22 & (10)^{*} \\
9 & (2)^{*}\end{aligned}$ & $\begin{array}{l}88 \\
45 \\
18\end{array}$ \\
\hline Total & 34 & 100 & 15 & 100 & 49 & 100 \\
\hline
\end{tabular}

* May have been present but there was insufficient documented information to be certain.

$\mathrm{NE}$, neonatal encephalopathy.

proceedings. This reduces the educational benefits arising from the findings since they can only be fed back in an aggregated form at a regional level. Unlike the CESDI results, results from the neonatal encephalopathy enquiries have been fed back to individual units on request. The units have informed us that this is a very useful process that has given staff insight into how standards of care are perceived by external reviewers. For example, it has emphasised the importance of clarity in the recording of events in the case notes and the need for clear decisions about management which are then unambiguously communicated to staff and parents. The recent review of confidential enquiries has recommended that "The guarantee of confidentially (offered by the confidential enquiries to clinicians) can and should be combined with feedback of assessments of case management to individual clinicians and clinical teams." ${ }^{\prime 11}$ 
In this study we have extended the confidential enquiry process to look at severe morbidity and not just mortality. We know that some of the encephalopathy cases died subsequently and indeed some of the neonatal deaths may have been encephalopathic prior to death. Clearly, death by 28 days of life is a somewhat arbitrary cut off to discriminate between cases whose antecedents may be the same or may have resulted from a similar pathway of events. Furthermore, from a clinical governance point of view, the practice of focusing on deaths alone is equally unsatisfactory. Changes to practice that reduce mortality rates but ignore the effect on serious morbidity can hardly be considered "good quality

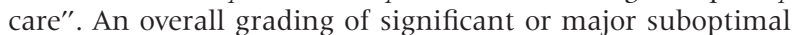
care was judged to have occurred for between two thirds and three quarters of the encephalopathy cases and the deaths respectively. Only 14\% of encephalopathy cases and 15\% of deaths were judged to have an overall grading of no suboptimal care.

Overall the nature of the episodes of suboptimal care was similar for both the encephalopathy cases and the deaths. Nearly $90 \%$ of encephalopathy cases had evidence of a peripartum insult, although the insult alone was thought likely to account for the clinical condition of only $45 \%$ of cases. These data imply that "better" care might reduce the incidence of neonatal encephalopathy by half. However, there are several caveats to this interpretation. First, it should be noted that we only included those cases of encephalopathy who survived the neonatal period and the neonatal case fatality has been estimated to be about $10 \%{ }^{4}$ Second, since we had relatively little information about antenatal circumstances and events, and this information had not been collected systematically, the role of such potential risk factors ${ }^{4}$ could not be fully evaluated. Third, whilst we included all cases in Trent Region who fulfilled the case definition during a one year period, this was a small population. Finally, it is important to note that due to limited antenatal data and the fact that confidential enquiries are based on case series with no comparison control data it is possible that episodes of suboptimal care occur relatively commonly, but they only have an adverse effect on compromised or already "damaged" fetuses. It is, in practice, possible to include controls, as is currently being demonstrated by the CESDI investigation of deaths of 27 and 28 week infants. ${ }^{14}{ }^{15}$ However funding for this study was inadequate to allow the inclusion of controls despite the additional advantages that would have resulted.

Confidential enquires are good at identifying obvious and blatant deviations from accepted practice, for example, lack of staff skilled in neonatal resuscitation and lack of resuscitation equipment. Less obvious deviations from good practice require the availability of a broad range of explicit standards of care against which the quality of care provided can be compared. The paucity of agreed evidence based standards is a limiting factor in the conduct of CESDI and similarly limited our encephalopathy enquiries. It is clear that there is a need to develop such explicit standards to improve the quality and consistency of both the enquiry data and process. The validity of CESDI enquiry panel decisions has been investigated..$^{76}$ Factors influencing the conduct and decisions of panels include the role and influence of the chair, the composition of the panel, the interests of the panel members, and how much guidance the panels received on grading the cases. We endeavoured to overcome these limitations by using the same neutral chair for all the panels, by the inclusion of a single representative from each specialty and by providing clear guidance on the grading of cases. Nevertheless, we and others, recognise the shortcomings of using panels of experts to reach consensus decisions..$^{17} 18$

It is likely that some of the events that result in neonatal death would, in slightly different circumstances, have resulted in serious morbidity and/or disability. Since coming under the auspices of the National Institute for Clinical Excellence, the future of the confidential enquiries is under debate. It is therefore opportune to consider the feasibility and rationale for expanding the use of the confidential enquiry method to investigate the circumstances surrounding cases other than deaths, such as those with serious morbidity. We have demonstrated that with minor adaptations the enquiry method used in CESDI can be usefully applied to investigate the quality of care provided to cases of neonatal encephalopathy. Death is an unambiguous event. In contrast, "near miss" and other potentially preventable events may be less obvious and the use of clear, valid, agreed, practical, and reproducible definitions of what constitutes a case is essential. Our example of using a condition as heterogeneous as neonatal encephalopathy illustrates that this is feasible. Since enquiry panels are expensive in terms of the opportunity costs of senior staff time they could be used in specific circumstances rather than for all cases. For example by selecting a random sample of all cases across a region or (as we have already carried out in practice) a panel could be convened to review all cases in a single unit where an excess of cases has been identified.

We have demonstrated that it is possible, with minimal alteration, to apply the CESDI method to specific important "near miss" cases of morbidity. We see no reason why the enquiry approach could not be expanded to other "near miss" events or other serious morbid events with a preventable component.

\section{ACKNOWLEDGEMENTS}

We would like to thank the Trent CESDI office staff, Sue Wood, Jayne Bennett, and Michelle Birds; all participants in the enquiry panels and the Trent Neonatal Survey nurses.

\section{Funding}

Trent CESDI was funded via the Maternal and Child Health Research Consortium. The Trent Neonatal Survey is funded from a regional levy comprising contributions from all district health authorities in Trent. ESD is funded by Leicestershire District Health Authority, JJK is funded by a National Career Scientist Award from the Department of Health and NHS R\&D (PHCS 022).

\section{Conflict of Interest}

None.

\section{Contributions}

ESD contributed to the conception, design, execution, analysis, interpretation, and paper writing. JJK contributed to the analysis, interpretation, and paper writing. CRL contributed to the execution, analysis, interpretation, and edited the paper. MC contributed to the design, interpretation, and paper writing. DJ contributed to the conception, design, execution, and edited the paper. DF contributed to the conception, design, execution, analysis, interpretation, and paper writing.

Authors' affiliations

E S Draper, J J Kurinczuk, C R Lamming, M Clarke, Department of

Epidemiology and Public Health, University of Leicester, Leicester, UK

D James, Department of Reproductive Medicine, University of

Nottingham, Nottingham, UK

D Field, Department of Child Health, University of Leicester, Leicester, UK

\section{REFERENCES}

1 Nelson KB, Leviton A. How much of neonatal encephalopathy is due to birth asphyxia? Am J Dis Child 1991;145:1325-31.

2 Derham RJ, Matthews TG, Clarke TA. Early seizures indicate quality of perinatal care. Arch Dis Child 1985;60:809-13.

3 Adamson SJ, Alessandri LM, Badawi N, et al. Predictors of neonatal encephalopathy in full-term infants. BN 1995;311:598-602.

4 Badawi N, Kurinczuk JJ, Keogh JM, et al. Antepartum risk factors for newborn encephalopathy: the Western Australian case control study. BM 1998:317:1549-53.

5 Badawi N, Kurinczuk JJ, Keogh JM, et al. Intrapartum risk factors for newborn encephalopathy: the Western Australian case control study. BM 1998;317:1554-8.

6 Ellis M, Manandhar N, Manandhar DS, et al. Risk factors for neonatal encephalopathy in Kathmandu, Nepal, a developing country: unmatched case-control study. BM 2000;320:1229-36. 
7 Confidential Enquiry into Stillbirths and Deaths in Infancy (CESDI) Annual Report for 1 January-31 December 1993. Part 1: summary of methods and main results. London: Department of Health, 1995.

8 Clarke M, Draper ES, James D, et al. Confidential Enquiry into Stillbirths and Deaths in Infancy (CESDI) 1997. One of the Trent infant mortality and morbidity studies. Leicester: Trent Institute For Health Services Research, 1998:45-7.

9 Field DJ, Draper ES. Trent Neonatal Survey Report 1997-one of the Trent infant mortality and morbidity studies. Leicester: Trent Institute for Health Services Research, 1998:1-70.

10 Sarnat HB, Sarnat MS. Neonatal encephalopathy following fetal distress. Arch Neurol 1976;33:598-705.

11 Grimley Evans J. Review of confidential enquiries for the National Institute for Clinical Excellence. London: National Institute for Clinical Excellence, 2000.

12 Donaldson RJ, Donaldson LJ. Essential public health medicine. London: Kluwer Academic Publishers, 1993.
13 Derrington MC, Gallimore S. The effect of the National Confidential Enquiry into Perioperative Deaths on clinical practice. Report of a postal survey of a sample of consultant anaesthetists. Anaesthesia 1997;52:3-8.

14 Draper ES, Kurinczuk JJ, Abrams KR, et al. Assessment of the separate contributions to perinatal mortality of infertility history and treatment: a case-control analysis. Lancet 1999;353:1746-9.

15 Confidential Enquiry into Stillbirths and Deaths in Infancy (CESDI). 6th Annual Report. London: Maternal and Child Health Consortium, 6th Annua 1999.

16 Confidential Enquiry into Stillbirths and Deaths in Infancy (CESDI). 5th Annual Report. London: Maternal \& Child Health Consortium, 1998.

17 Coulter I, Adams A, Shekelle P. Impact of varying panel membership on ratings of appropriateness in concensus panels: a comparison of a multiand single disciplinary panel. Health Services Research 1995:30:577-91.

18 Scott EA, Black N. When does consensus exist in expert panels? J Public Health Med 1991;13:35-9.

\section{ADC web submission and review system}

The Editors of $A D C$ are pleased to inform authors and reviewers of its new online submission and review system. Developed by Highwire Press (CA, USA), Bench>Press is a fully integrated electronic system which uses the internet to allow rapid and efficient submission of manuscripts, and for the peer review process to be conducted entirely online. We are the first journal of the BM publishing group to go online in this way; the aim, apart from saving trees, is to speed up the frequently frustrating progress from submission to publication.

Authors can submit their manuscript in any standard word processing software. Standard graphic formats acceptaed include: .jpg, .tiff, .gif, eps, etc. The text and graphic files are automatically converted to PDF for ease of distribution and reviewing purposes. Authors are asked to approve their submission before it formally enters the reviewing process. On approval, the submission is passed to the editor and/or reviewers via the web. All transactions are secure.

To access the system click on "SUBMIT YOUR MANUSCRIPT HERE" on the ADC homepage: http://www.archdischild.com, or you can access the submission site directly at http://submitadc.bmijournals.com.

We are very excited with this new development and would encourage authors and reviewers to use the system where possible. It is simple to use and should greatly improve on the current peer review process. Full instructions can be found on Bench>Press and ADC online. 